\title{
G/R 241 Polymorphism of Intercellular Adhesion Molecule 1 (ICAM-1) Is Associated with Fuchs Uveitis
}

\author{
Luca Cimino, ${ }^{1,2}$ Luigi Boiardi, ${ }^{3}$ Raffaella Aldigeri, ${ }^{4}$ Bruno Casali, ${ }^{5}$ Davide Nicoli, ${ }^{5}$ \\ Enrico Farnetti, ${ }^{5}$ Carlo Salvarani, ${ }^{3}$ Daniele Cirone, ${ }^{2}$ Liberatina De Martino, ${ }^{2}$ \\ Alessandro Pupino, ${ }^{2}$ and Luca Cappuccini ${ }^{2}$
}

Purpose. To investigate potential associations of the ICAM-1 gene polymorphisms and Fuchs uveitis in a cohort of Italian patients.

Methods. Seventy-one consecutive Italian patients affected by Fuchs uveitis were observed at the Ocular Immunology Unit, Arcispedale S. Maria Nuova (Reggio Emilia, Italy) from 2002 to 2008. Two hundred twenty-six healthy Italian blood donors from the same geographic area were selected as the control group. All Fuchs uveitis patients and control subjects were genotyped by polymerase chain reaction (PCR) and allelespecific oligonucleotide techniques for ICAM-1 polymorphisms at codon 241 (exon 4).

Results. The frequency of the ICAM-1 G/R 241 polymorphism was significantly higher in Fuchs uveitis than in the control subjects $\left(16.9 \%\right.$ vs. $5.8 \% ; P=0.006, P_{\text {corr }}=0.012$; odds ratio, $3.3 ; 95 \%$ confidence interval, $1.4-7.7)$. No significant association between clinical features and ICAM-1 polymorphisms was found.

Conclusions. This study demonstrates for the first time that the ICAM-1 G/R 241 polymorphism may represent a candidate gene for Fuchs uveitis susceptibility. (Invest Ophthalmol Vis Sci. 2010;51:4447-4450) DOI:10.1167/iovs.09-4669

Thtercellular adhesion molecule-1 (ICAM-1; CD54), a 90-kDa 1 member of the immunoglobulin (Ig) superfamily, is expressed on the surface of several cell types including leukocytes, endothelial cells, and proliferating intimal smooth muscle cells. Its ligands are the membrane-bound $\beta 2$-integrin receptors LFA-1 (CD11a, CD18) and Mac-1 (CD11b, CD18) on leukocytes, although several other ligands have been described. ${ }^{1}$ ICAM-1 is critical in the firm arrest and transmigration of leukocytes out of blood vessels and into tissues. ${ }^{2}$ ICAM-1 is present on endothelial cells and all leukocytes, where it acts both as an adhesion ${ }^{2}$ and a signaling ${ }^{3-6}$ molecule, and its expression is enhanced by different cytokines, including tumor necrosis factor (TNF), interferon- $\gamma$, and interleukin-1. Endothelial expression of ICAM-1 is increased in atherosclerotic and transplant-associated atherosclerotic tissue and in animal mod-

From the ${ }^{1}$ Ocular Immunology Unit, ${ }^{2}$ Ophthalmology Unit, ${ }^{3}$ Rheumatology Unit, and ${ }^{5}$ Molecular Biology Laboratory, Arcispedale S Maria Nuova Reggio Emilia, Italy; and the ${ }^{4}$ Institute of Ophthalmology, University of Parma, Parma, Italy.

Submitted for publication September 21, 2009; revised February 2 and March 23, 2010; accepted April 9, 2010.

Disclosure: L. Cimino, None; L. Boiardi, None; R. Aldigeri, None; B. Casali, None; D. Nicoli, None; E. Farnetti, None; C. Salvarani, None; D. Cirone, None; L. De Martino, None; A. Pupino, None; L. Cappuccini, None

Corresponding author: Luca Cimino, Ocular Immunology Unit, Ophthalmology, Unit, Arcispedale S Maria Nuova Reggio, Viale Risorgimento, 80 Reggio, Emilia, 42123 Italy; 1.cimino@libero.it. els of atherosclerosis, ${ }^{7-9}$ and it has been implicated in the progression of autoimmune diseases, including rheumatoid arthritis, multiple sclerosis, and type I diabetes. ${ }^{10-13}$

Several ICAM-1 coding region biallelic polymorphisms have been described in the human ICAM-1 gene, including those located in exons 4 and 6 , thereby modifying codons 241 and 469 , respectively. ${ }^{14} \mathrm{G} 241 \mathrm{R}$ (glycine/arginine) is located within the third Ig-like domain, shown to be the Mac-1 binding domain, ${ }^{15}$ and therefore is of potential importance during leukocyte transmigration. The hypothesis is that, since the ICAM-1 gene polymorphisms are located in exons and lead to amino acid substitutions, they could alter ligand binding or the stability of the multimeric ICAM-1 on the cell surface and therefore alter signal transduction. Many studies have described associations between ICAM-1 polymorphisms and chronic inflammatory disorders, including ulcerative colitis and Crohn's disease, ${ }^{16,17}$ polymyalgia rheumatica, ${ }^{18}$ type I diabetes, ${ }^{19}$ multiple sclerosis, ${ }^{20}$ chronic allograft vasculopathy, ${ }^{21,22}$ peripheral occlusive vascular disease, ${ }^{23,24}$ and myocardial infarction. ${ }^{25} \mathrm{How}$ ever, there is no consensus as to which alleles are protective and which are detrimental. Interpretation of these clinical associations is hindered by lack of understanding of the functional significance of ICAM-1 polymorphisms.

Fuchs uveitis is a chronic inflammatory eye disease of unknown etiology that usually presents as a unilateral anterior uveitis in young adults. It is often characterized by an insidious onset and is frequently misdiagnosed; complications include cataract formation and secondary glaucoma. Several theories have been suggested regarding its etiology, including an immunologic disorder characterized by elevated levels of immunoglobulin $\mathrm{G}$ in aqueous humor of patients ${ }^{26,27}$ and $\mathrm{CD}^{+}$cells. $^{28}$ Recent findings have suggested that an infectious agent such as Toxoplasma gondii ${ }^{29,30}$ or Rubella virus ${ }^{31,32}$ could act as a trigger of eye inflammation.

ICAM-1 has been shown to play an important role in the induction and development of inflammation in uveitis in both in vitro and in vivo animal studies. ${ }^{33-36} \mathrm{La}$ Heij et al ${ }^{33}$ found a significantly increased expression of adhesion molecules in the iris of patients affected by uveitis, including Fuchs uveitis, suggesting an immunoregulatory function for adhesion molecules in the pathogenesis of uveitis.

We postulated that the polymorphism of the ICAM-1 gene $(-241)$ represents a candidate gene for disease susceptibility in Fuchs uveitis.

\section{Materials ANd Methods}

\section{Subjects}

The study protocol adhered to the tenets of the Declaration of Helsinki and was approved by the local institutional review board. Informed consent was obtained from patients and control subjects before they were included in the study. 
TABLE 1. Demographic and Clinical Features of Patients with Fuchs Uveitis

\begin{tabular}{lcc}
\hline & \multicolumn{2}{c}{ Patients $(\boldsymbol{n}=\mathbf{7 1})$} \\
\cline { 2 - 3 } & $\boldsymbol{n}$ & $\%$ \\
\hline Male & 39 & 54.9 \\
Female & 32 & 45.1 \\
Mean age in years \pm SD & $42 \pm 15$ & - \\
Keratic precipitates & 53 & 74.6 \\
Iris atrophy & 65 & 91 \\
Heterochromia & 35 & 49.3 \\
Cataract & 26 & 36.6 \\
Glaucoma & 9 & 12.7 \\
Vitreitis & 63 & 88.7 \\
Unilateral & 65 & 91.5 \\
Vitrectomy & 4 & 5.6 \\
\end{tabular}

From May 2002 to June 2008, 71 consecutive patients with Fuchs uveitis were examined at the Immunology Ocular Unit, Arcispedale S. Maria Nuova Hospital (Reggio Emilia, northern Italy). Demographic data and ocular findings (Table 1) and laboratory tests were recorded in a computer database.

Details on laterality, chronicity, and ocular signs were included. Patients with uveitis and associated underlying systemic diseases were excluded. The study included 226 healthy subjects who were unrelated blood donor volunteers.

The diagnosis of Fuchs uveitis was based on the presence of the following clinical features: unilateral uveitis involving the anterior segment and the vitreous body, absence of acute symptoms (pain, photophobia), characteristic Fuchs stellate keratic, sparsely distributed precipitates, diffuse iris stromal atrophy with or without heterochromia, vitritis, absence of synechiae, and the absence of cystoid macular edema. $^{37}$

All the study subjects were Caucasians residing in Italy for at least one generation. No ethnic differences were present between patients and control subjects.

\section{Molecular Analysis of the ICAM-1 Polymorphism}

Genomic DNA was extracted by phenol-chloroform standard method from $500 \mu \mathrm{L}$ whole blood collected in edetic acid. To detect the substitution of arginine for glycine responsible for the ICAM-1 polymorphism G/R 241 in exon 4 of the ICAM-1 gene, we developed an allele-specific polymerase chain reaction (ASPCR) method. We designated allele-specific primers 5'-CGTGGTCTGTTCCCTGGACG-3', 5'CGTGGTCTGTTCCCTGGACA-3' (nucleotide number 638-657), using published sequence information on the point mutation of the ICAM-1 gene,${ }^{38}$ and common primer 5'-GTCGTTGCCATAGGTGACTG-3'8. As an internal positive control, an additional primer pair for the glycoprotein IIIa gene ${ }^{39}$ was used in all ASPCRs, with a pair of primers consisting of an allele-specific primer and a common primer, according to the method of Bein et al. ${ }^{40}$ The positive control primer pair amplified the 247-bp fragment of glycoprotein IIIa gene. The ASPCR was performed in a total volume of $50 \mu \mathrm{L}$ that contained $0.2 \mu \mathrm{g}$ genomic DNA, each primer pair consisting of 20 picomoles of allele-specific primer and 20 picomoles of common primer, 15 picomoles of each positive control primer, $200 \mu \mathrm{M}$ each dNTP, $10 \mathrm{mM}$ Tris-HCl (pH 8.3), $50 \mathrm{nM} \mathrm{KCl}, 1.5 \mathrm{mM} \mathrm{MgCl}_{2}$, and 1.5 units of DNA polymerase (AmpliTaq; Perkin-Elmer, Waltham, MA). The PCR reaction was performed for 35 cycles, each consisting of a denaturation step at $95^{\circ} \mathrm{C}$ for 30 seconds, $68^{\circ} \mathrm{C}$ for 30 seconds, and $72^{\circ} \mathrm{C}$ for 30 seconds in a PCR system (GeneAmp PCR System 9600; Perkin Elmer). The amplified PCR products were analyzed by $2 \%$ agarose gel electrophoresis followed by ethidium bromide staining and ultraviolet visualization.

\section{Statistical Analysis}

The frequencies of the alleles and genotypes between patient and control groups were compared by means of $\chi^{2}$ test. Odds ratios (ORs) were calculated together with 95\% confidence intervals (CIs). Corrected $P$ values were calculated by multiplying $P$ by the number of alleles compared (SPSS statistical package; SPSS Inc., Chicago, IL).

Statistical analysis to define population sample size and statistical power was performed with PAWE software (PAWE version 1.2, February 2003 written by Derek Gordon assisted by Michael Nothnagel, Rockefeller University, New York, NY). ${ }^{41-45}$

\section{Results}

The demographic and clinical features of patients are reported in Table 1 . Thirty-nine (55\%) patients were male and 32 (45\%) were female. The mean age was 42 years (range, $8-78$ years). Eye findings included stellate keratic precipitates in $53(75 \%)$ cases, vitritis in $63(89 \%)$, iris atrophy in 65 (91\%), and heterochromia in 35 (49\%). Fuchs uveitis was mostly unilateral (91\%). Twenty-six (14\%) patients presented with cataract and nine (13\%) with glaucoma.

The allele and genotype frequencies of G/R 241 in patients and controls are reported in Table 2.

Allele $\mathrm{R}$ was significantly more frequent in the uveitis patients than in the control subjects $\left(P=0.001, P_{\text {corr }}=0.002\right.$; OR, 3.7; 95\% CI, 1.7-7.9), and the carriage rate of R241 was significantly higher in the patients than in the control subjects (16.9\% vs. $5.8 \% ; P=0.006 ; P_{\text {corr }}=0.012 ; \mathrm{OR}, 3.3 ; 95 \% \mathrm{CI}$, $1.4-7.7)$. Furthermore, the distribution of the G/R 241 geno-

TABLE 2. Frequencies of Alleles, Genotypes, and Carriage Rates of ICAM-1 G/R 241 Polymorphism in Fuchs Uveitis Cases and Controls

\begin{tabular}{|c|c|c|c|c|c|c|c|}
\hline & \multicolumn{2}{|c|}{$\begin{array}{l}\text { Fuchs Uveitis } \\
\qquad(n=71)\end{array}$} & \multicolumn{2}{|c|}{ Controls $(n=226)$} & \multirow[b]{2}{*}{$\boldsymbol{P}$} & \multirow[b]{2}{*}{$P_{\text {corr }}$} & \multirow[b]{2}{*}{ OR $(95 \%$ CI $)$} \\
\hline & $\boldsymbol{n}$ & $\%$ & $\boldsymbol{n}$ & $\%$ & & & \\
\hline \multicolumn{8}{|l|}{ Allele } \\
\hline $\mathrm{R}$ & $15 / 142$ & 10.6 & $14 / 452$ & 3.1 & 0.001 & 0.002 & $3.7(1.7-7.9)$ \\
\hline G & $127 / 142$ & 89.4 & $438 / 452$ & 96.9 & & & \\
\hline \multicolumn{8}{|l|}{ Genotype } \\
\hline $\mathrm{R} / \mathrm{R}$ & $03 / 71$ & 4.2 & $01 / 226$ & 0.4 & 0.005 & 0.015 & \\
\hline $\mathrm{R} / \mathrm{G}$ & $09 / 71$ & 12.7 & $12 / 226$ & 5.3 & & & \\
\hline $\mathrm{G} / \mathrm{G}$ & $59 / 71$ & 83.1 & $213 / 226$ & 94.2 & & & \\
\hline \multicolumn{8}{|l|}{ Carriage rate } \\
\hline $\mathrm{R} / \mathrm{R}+\mathrm{R} / \mathrm{G}$ & $12 / 71$ & 16.9 & $11 / 226$ & 5.8 & 0.006 & 0.012 & $3.3(1.4-7.7)$ \\
\hline $\mathrm{G} / \mathrm{G}$ & $59 / 71$ & 83.1 & $213 / 226$ & 94.2 & & & \\
\hline $\mathrm{R} / \mathrm{R}$ & $3 / 71$ & 4.2 & $1 / 226$ & 0.4 & 0.044 & 0.088 & $9.9(1.0-97.0)$ \\
\hline$R / G+G / G$ & $68 / 76$ & 95.8 & $225 / 226$ & 99.6 & & & \\
\hline
\end{tabular}


type differed significantly between the patients and control subjects $\left(P=0.005 ; P_{\text {corr }}=0.015\right)$.

Sample size and the allele frequencies of the G/R 241 polymorphism provided a statistical power of more than $90 \%$ for genotypic test and more than 95\% for allelic test. No association was found between clinical features and the frequencies of genotypes.

\section{Discussion}

Intercellular adhesion molecules play an important role in the recruitment of specific $\mathrm{T}$ lymphocytes from the blood stream into inflamed tissue. ICAM-1 has been proven to be important in the induction and development of inflammation in uveitis, whether or not it is associated with systemic disease, both in vitro and in vivo animal studies. Furthermore, Whitcup et al. ${ }^{46}$ reported that serum ICAM-1 levels were higher in patients with uveitis than in normal control subjects and were significantly higher in patients with uveitis associated with an underlying systemic disease than in those without systemic disease. In contrast, other studies reported that serum ICAM-1 levels in accompanying systemic disease were similar to those in isolated uveitis. ${ }^{47-49}$ To date, ICAM polymorphisms, particularly G/R 241 polymorphism, have been studied in Behçet disease, polymyalgia rheumatica/giant cell arthritis, and rheumatoid arthritis. ${ }^{50-52}$ We hypothesized that G/R 241 polymorphism of ICAM-1 could be associated with Fuchs uveitis. The molecular analysis of ICAM-1 gene confirmed that G/R 241 polymorphism frequency was higher in patients affected by Fuchs uveitis than in control subjects, confirming that it could represent a risk factor for this ocular entity.

A recent experimental study on the functional significance of ICAM-1 polymorphisms, in terms of cell surface expression of ICAM-1 and leukocyte adhesion to human endothelial cells, confirmed that the genotype G241/E469 was associated with greater cell surface expression, leading to greater adhesion of leukocytes. ${ }^{53}$ This finding could explain the described associations of ICAM polymorphisms with chronic inflammatory disease.

In their study on the correlation between genetic polymorphism and circulating soluble ICAM-1 in a healthy population, Ponthieux et al. ${ }^{54}$ confirmed a significant association between R241 allele and lower serum ICAM-1 levels, probably due to the binding impairment of ICAM-1 to leukocyte integrin Mac-1 protein. We found a significant increase in the R241 allele in Fuchs uveitis in our population compared with that in the control subjects, and this increase may explain the chronic low-grade inflammation response in this disease.

Most Fuchs patients present with minimal anterior chamber inflammation, and therapy is not required. Symptomatic flareups may require short-term topical corticosteroids. However, long-term therapy is not indicated. Theoretically, variations of serum protein levels may be influenced by disease activity, systemic manifestations or systemic therapy. These fluctuating influences may explain why our results are different from those in earlier studies of serum ICAM-1 levels. On the other hand, disease activity and systemic therapy should not affect gene polymorphisms, as reported in our study.

To our knowledge, an association between ICAM-1 polymorphisms and Fuchs uveitis has never been reported. Since Fuchs uveitis represents a frequent cause of uveitis in our region, and the etiology is still unknown, this study could be a first step in understanding whether this polymorphism represents a risk factor for this ocular disease.

\section{References}

1. van de Stolpe A, van der Saag PT. Intercellular adhesion molecule-1. J Mol Med. 1996;74:13-33.
2. Springer TA. Traffic signals for lymphocyte recirculation and leukocyte emigration: the multistep paradigm. Cell. 1994;76:301-314.

3. Lidington EA, Moyes DL, McCormack AM, Rose ML. A comparison of primary endothelial cells and endothelial cell lines for studies of immune interactions. Transpl Immunol. 1999;7:239-246.

4. Lawson C, Ainsworth M, Yacoub M, Rose M. Ligation of ICAM-1 on endothelial cells leads to expression of VCAM-1 via a nuclear factor-kappaB-independent mechanism. J Immunol. 1999;162: 2990-2996

5. Lawson C, Ainsworth ME, McCormack AM, Yacoub M, Rose ML. Effects of cross-linking ICAM-1 on the surface of human vascular smooth muscle cells: induction of VCAM-1 but no proliferation. Cardiovasc Res. 2001;50:547-555.

6. Lawson C, Holder AL, Stanford RE, Smith J, Rose ML. Anti-intercellular adhesion molecule- 1 antibodies in sera of heart transplant recipients: a role in endothelial cell activation. Transplantation. 2005;80:264-271.

7. Iiyama K, Hajra L, Iiyama M, et al. Patterns of vascular cell adhesion molecule-1 and intercellular adhesion molecule-1 expression in rabbit and mouse atherosclerotic lesions and at sites predisposed to lesion formation. Circ Res. 1999;85:199-207.

8. Poston RN, Haskard DO, Coucher JR, Gall NP, Johnson-Tidey RR. Expression of intercellular adhesion molecule- 1 in atherosclerotic plaques. Am J Patbol. 1992;140:665-673.

9. Printseva O, Peclo MM, Gown AM. Various cell types in human atherosclerotic lesions express ICAM-1: further immunocytochemical and immunochemical studies employing monoclonal antibody 10F3. Am J Patbol. 1992;140:889-896.

10. Bertry-Coussot L, Lucas B, Danel C, et al. Long-term reversal of established autoimmunity upon transient blockade of the LFA-1/ intercellular adhesion molecule-1 pathway. J Immunol. 2002;168: 3641-3648.

11. Dietrich JB. The adhesion molecule ICAM-1 and its regulation in relation with the blood-brain barrier. J Neuroimmunol. 2002; 128:58-68.

12. Kawai K, Kobayashi $Y$, Shiratori M, et al. Intrathecal administration of antibodies against LFA-1 and against ICAM-1 suppresses experimental allergic encephalomyelitis in rats. Cell Immunol. 1996; 171:262-268

13. McMurray $\mathrm{RW}$, Tang $\mathrm{H}$, Braley-Mullen $\mathrm{H}$. The role of alpha 4 integrin and intercellular adhesion molecule-1 (ICAM-1) in murine experimental autoimmune thyroiditis. Autoimmunity. 1996;23:9-23.

14. Vora DK, Rosenbloom CL, Beaudet AL, Cottingham RW. Polymorphisms and linkage analysis for ICAM-1 and the selectin gene cluster. Genomics. 1994;21:473-477.

15. Diamond MS, Staunton DE, Marlin SD, Springer TA. Binding of the integrin Mac-1 (CD11b/CD18) to the third immunoglobulin-like domain of ICAM-1 (CD54) and its regulation by glycosylation. Cell. 1991;65:961-971.

16. Yang H. Analysis of ICAM-1 gene polymorphism in immunologic subsets of inflammatory bowel disease. Exp Clin Immunogenet. 1997; 14:214-225.

17. Yang H, Vora DK, Targan SR, Toyoda H, Beaudet AL, Rotter JI. Intercellular adhesion molecule 1 gene associations with immunologic subsets of inflammatory bowel disease. Gastroenterology. 1995; $109: 440-448$.

18. Amoli MM, Shelley E, Mattey DL, et al. Intercellular adhesion molecule-1 gene polymorphisms in isolated polymyalgia rheumatica. J Rbeumatol. 2002;29:502-504.

19. Kristiansen OP, Nolsoe RL, Holst H, et al. The intercellular adhesion molecule-1 K469E polymorphism in type 1 diabetes. Immunogenetics. 2000;52:107-111.

20. Mycko MP, Kwinkowski M, Tronczynska E, Szymanska B, Selmaj $\mathrm{KW}$. Multiple sclerosis: the increased frequency of the ICAM-1 exon 6 gene point mutation genetic type K469. Ann Neurol. 1998; $44: 70-75$.

21. Borozdenkova S, Smith J, Marshall S, Yacoub M, Rose M. Identification of ICAM-1 polymorphism that is associated with protection from transplant associated vasculopathy after cardiac transplantation. Hum Immunol. 2001;62:247-255. 
22. McLaren AJ, Marshall SE, Haldar NA, et al. Adhesion molecule polymorphisms in chronic renal allograft failure. Kidney Int. 1999; 55:1977-1982.

23. Flex A, Gaetani E, Angelini F, et al. Pro-inflammatory genetic profiles in subjects with peripheral arterial occlusive disease and critical limb ischemia. J Intern Med. 2007;262:124-130.

24. Gaetani E, Flex A, Pola R, et al. The K469E polymorphism of the ICAM-1 gene is a risk factor for peripheral arterial occlusive disease. Blood Coagul Fibrinolysis. 2002;13:483-488.

25. Jiang $\mathrm{H}$, Klein RM, Niederacher $\mathrm{D}$, et al. C/T polymorphism of the intercellular adhesion molecule-1 gene (exon 6, codon 469): a risk factor for coronary heart disease and myocardial infarction. Int J Cardiol. 2002;84:171-177.

26. Murray PI, Hoekzema R, Luyendijk L, Konings S, Kijlstra A. Analysis of aqueous humor immunoglobulin $G$ in uveitis by enzyme-linked immunosorbent assay, isoelectric focusing, and immunoblotting. Invest Ophthalmol Vis Sci. 1990;10:2129-2135.

27. Bloch-Michel E, Lambin P, Debbia M, Tounsi Y, Trichet C, Offret $H$ Local production of IgG and IgG subclasses in the aqueous humor of patients with Fuchs heterochromic cyclitis, herpetic uveitis and toxoplasmic chorioretinitis. Int Ophthalmol. 1997-1998;21:187194.

28. Muhaya M, Calder V, Towler HM, Shaer B, McLauchlan M, Lightman S. Characterization of $\mathrm{T}$ cells and cytokines in the aqueous humour (AH) in patients with Fuchs' heterochromic cyclitis (FHC) and idiopathic anterior uveitis (IAU). Clin Exp Immunol. 1998;111:123-128.

29. La Hey E, de Jong PT, Kijlstra A. Fuchs' heterochromic cyclitis: review of the literature on the pathogenetic mechanisms. $\mathrm{Br} \mathrm{J}$ Ophthalmol. 1994;78:307-312.

30. La Hey E, Rothova A, Baarsma GS, de Vries J, van Knapen F, Kijlstra A. Fuchs' heterochromic iridocyclitis is not associated with ocular toxoplasmosis. Arch Ophthalmol. 1992;110:806-811.

31. Quentin CD, Reiber H. Fuchs heterochromic cyclitis: rubella virus antibodies and genome in aqueous humor. Am J Ophthalmol. 2004; 138:46-54.

32. de Groot-Mijnes JD, de Visser L, Rothova A, Schuller M, van Loon AM, Weersink AJ. Rubella virus is associated with fuchs heterochromic iridocyclitis. Am J Ophthalmol. 2006;141:212-214.

33. La Heij E, Kuijpers RW, Baarsma SG, Kijlstra A, van der Weiden M, Mooy CM. Adhesion molecules in iris biopsy specimens from patients with uveitis. Br J Ophthalmol. 1998;82:432- 437.

34. Parnaby-Price A, Stanford MR, Biggerstaff J, et al. Leukocyte trafficking in the experimental autoimmune uveitis in vivo.J Leukoc Biol. 1998;64:434-440.

35. Kanagawa T, Matsuda S, Mikawa Y, et al. Role of ICAM-1 and LFA-1 in endotoxin-induced uveitis in mice. Jpn J Ophthalmol. 1996;40: $174-180$.

36. Devine L, Lightman SL, Greenwood J. Role of LFA-1, ICAM-1, VLA-4 and VCAM-1 in lymphocyte migration across retinal pigment epithelial monolayers in vitro. Immunology. 1996;88:456-462.32.

37. Gupta A, GuptaV, Herbort CP, Khairallah M. Uveitis Test and Imaging. New Delhi, India: Jaypee Brothers Medical Publishers; 2009:323-332.

38. Rothlein R, Czajkowski M, O'Neill MM, Marlin SD, Mainolfi D, Meluzzi VJ. Induction of intercellular adhesion molecule 1 on primary and continuous cell lines by proinflammatory cytokines. J Immunol. 1988;141:1665-1669.

39. Newman PJ, Derbes RS, Aster RH. The human platelet alloantigens PIA1 and PIA2 are associated with a Leucine 33/Proline 33 amino acid polymorphism in membrane glycoprotein IIIa and are distinguishable by DNA typing. J Clin Invest. 1989;83:1778-1781.

40. Bein G, Glaser R, Kirchner H. Rapid HLA-DRB1 genotyping by nested PCR amplification. Tissue Antigens. 1992;39:68-73.

41. Gordon D, Finch SJ, Nothnagel M, Ott J. Power and sample size calculations for case-control genetic association tests when errors present: application to single nucleotide polymorphisms. Hum Hered. 2002;54:22-33.

42. Gordon D, Levenstien MA, Finch SJ, Ott J. Errors and linkage disequilibrium interact multiplicatively when computing sample sizes for genetic case-control association studies. Pac Symp Biocomput. 2003:490-501.

43. Gordon D, Heath SC, Liu X, Ott J. A transmission disequilibrium that allows for genotyping errors in the analysis of single-nucleotide polymorphism data. Am J Hum Genet. 2001;69:371-380

44. Douglas JA, Skol AD, Boehnke M. Probability of detection of genotyping errors and mutations as inheritance inconsistencies in nuclear-family data. Am J Hum Genet. 2002;70:487- 495.

45. Sobel E, Papp JC, Lange K. Detection and integration of genotyping errors in statistical genetics. Am J Hum Genet. 2002;70:496508.

46. Whitcup SM, Vistica BP, Magone MT, George RK. Elevated serum levels of soluble ICAM-1 in uveitis patients predict underlying systemic disease. Br J Ophthalmol. 1999;83:252-253.

47. Palmer HE, Zaman AG, Ellis BA, et al. Longitudinal analysis of soluble intercellular adhesion molecule 1 in retinal vasculitis patients. Eur J Clin Invest. 1996;26:686-691.

48. Zaman AG, Edelsten C, Stanford R, et al. Soluble intercellular adhesion molecule-1 (sICAM-1) as a marker of disease relapse in idiopathic uveoretinitis. Clin Exp Immunol. 1994;95:60 - 65.

49. Klok AM, Luyendijk L, Zaal MJW, Rothova A, Kijlstra A. Soluble ICAM-1 serum levels in patients with intermediate uveitis. $\mathrm{BrJ}$ Opbthalmol. 1999;83:847-851.

50. Boiardi L, Salvarani C, Casali B, et al. Intercellular adhesion molecule-1 gene polymorphisms in Behçet's disease. J Rheumatol. 2001;28:1283-1287.

51. Salvarani C, Casali B, Boiardi L, et al. Intercellular adhesion molecule 1 gene polymorphisms in polymyalgia rheumatica/giant cell arteritis: association with disease risk and severity. J Rheumatol. 2000;27:1215-1221

52. Macchioni P, Boiardi L, Casali B, Nicoli D, Farnetti E, Salvarani C. Intercellular adhesion molecule 1 (ICAM-1) gene polymorphisms in Italian patients with rheumatoid arthritis. Clin Exp Rheumatol. 2000; 18:553-558.

53. Holder AL, Wolf $\mathrm{S}$, Walshe $\mathrm{C}$, et al. Expression of endothelial intercellular adhesion molecule-1 is determined by genotype: effects on efficiency of leukocyte adhesion to human endothelial cells. Hum Immunol. 2008;69:71-78.

54. Ponthieux A, Lambert D, Herberth B, Droesch S, Pfister M, Visvikis S. Association between Gly 241 Arg ICAM-1 gene polymorphism and serum sICAM-1 concentration in the Stanislas cohort. Eur J Hum Genet. 2003;11:679-686. 